\title{
Commentary: Justifying Investing in NSQIP and New Technology
}

Paul M. Starker ${ }^{*}$, Bertram Chinn ${ }^{2}$

'Overlook Medical Center, Columbia University College of Physicians and Surgeons, New York, NY, USA

${ }^{2}$ Division of Colon and Rectal Surgery, Overlook Medical Center, Robert Wood Johnson Medical School, New Brunswick, NJ, USA

Article Info

Article Notes

Received: April 11, 2018

Accepted: May 03, 2018

\section{*Correspondence:}

Dr. Paul M. Starker MD FACS, Chairman of Surgery,

Overlook Medical Center Clinical Professor of Surgery,

Columbia University College of Physicians and Surgeons, New York; E-mail: pmstarker@att.net;

(C) 2018 Starker PM. This article is distributed under the terms of the Creative Commons Attribution 4.0 International License.
Medical reimbursements will be increasingly linked to patient outcomes, as the United States continues to evolve from a volumebased system to a value-based system ${ }^{1}$. By the end of 2018, the 'quality or value' of care a patient receives will determine half of Medicare payments received for alternative payment models and will determine the majority of Medicare fee-for-service payments received $^{2-4}$. Consequently, the clinical and economic ramifications of patient management and resource investments must be critically evaluated by clinical surgeons and surgical administrators. Healthcare professionals must proactively consider the 'surgical value' of every clinical decision, as patients' outcomes will continue to play an increasingly important role in reimbursement ${ }^{5-9}$.

The growing emphasis on improved patient outcomes clearly delineates the future outlook of payments to healthcare providers. Therefore, hospitals and physicians need to proactively adapt to this evolving payment system and look for ways to enhance the value of care. Value can be described as a quality to cost ratio, whereby decreasing costs or increasing quality positively impact the value of services provided.

As reducing costs in a healthcare setting may be challenging and negatively impact patient care, a way forward would be to focus on increasing the quality aspect of the value equation. Two ways a provider may achieve maximizing the quality of care is by investing in the American College of Surgeons National Surgical Quality Improvement Program (ACS NSQIP ${ }^{\circledR}$ or NSQIP) and/or by adopting technology proven to improve patient outcomes.

\section{Investing in NSQIP}

NSQIP is the best surgical benchmarking performance database that provides hospitals and physicians practicing in those hospitals with a quality improvement program to: (1) measure the quality of surgical outcomes to improve overall patient care; (2) compare the quality of surgical outcomes against a national standard; and (3) identify critical quality improvement opportunities. An important advantage of NSQIP is that, because of the rigorous data collection and 30-day patient outcome follow-up required to participate in the program, surgeons feel comfortable that the benchmark data is accurate and an acceptable standard. It should be noted that there is an upfront expense associated with participation in the program, and it is for this reason that only 586 U.S. hospitals have actually 
joined $^{10}$. As one expense example, at Overlook Medical Center (OMC) in Summit, New Jersey, the NSQIP data collection requirements alone led to the need to hire two nurses at an annual total cost of approximately $\$ 170,000$. These nurses on average review the more than 3600 cases performed at OMC each year. To encourage more hospitals to participate in NSQIP and to demonstrate the value of the program, direct costs must decrease to the point that the added hospital expense of participating in the program are offset by the improvements in quality.

In 2010, after convincing administration that the NSQIP program could help the hospital more smoothly transition to the new approach to healthcare reimbursement, OMC enrolled in the NSQIP database with the intent of identifying areas of opportunity for improvement and encouraging process changes that reduced the potential for these postoperative occurrences. One of these areas for improvement included reducing Superficial Surgical Site Infections (SSIs) in General and Colorectal Surgery. Implementing NSQIP over the course of five years, OMC was able to pursue process changes (e.g., reducing operating room traffic, placing a priority on daily terminal cleaning of all OR rooms, changing prep solutions to alcohol-based products, appropriately managing the containment of wounds, etc) and markedly reduce surgical site infection rates. General surgery SSIs reduced from nearly $3 \%$ in 2010 to $0.7 \%$ in 2015; while Colorectal surgery SSIs reduced from $8 \%$ in 2010 to $0.5 \%$ in 2015 (Table 1 ).

Since the process changes were implemented over a period of time, there is no way of determining which of these changes had the most significant impact on outcomes. However, as more and more of these changes were adopted over time, infection rates continued to drop. The NSQIP database calculations showed that the baseline costs associated with these SSI reductions alone as a result of these process changes saved OMC enough money to fund the NSQIP program. Certainly, when other reductions in complications and costs are factored in, OMC has saved a significant amount of money. Although OMC has not done an institutional review of costs or overall cost savings analysis, the NSQIP program has clearly demonstrated great value.

\section{Investing in New Technology}

Similar to the NSQIP program, the acquisition of a technology with a favorable performance profile (i.e., ability to reduce complications) comes with an upfront cost that can be justified over time. Such technology includes the SPY

Table 1. Decreasing trend in surgical site infections as a result of implementing NSQIP, 2010-2015.

\begin{tabular}{|l|c|c|c|c|c|c|}
\hline \multicolumn{1}{|c|}{ OMC } & $\mathbf{2 0 1 0}$ & $\mathbf{2 0 1 1}$ & $\mathbf{2 0 1 2}$ & $\mathbf{2 0 1 3}$ & $\mathbf{2 0 1 4}$ & $\mathbf{2 0 1 5}$ \\
\hline General Surgery & $2.9 \%$ & $2.5 \%$ & $2.4 \%$ & $1.97 \%$ & $1.5 \%$ & $0.7 \%$ \\
\hline Colorectal Surgery & $8.1 \%$ & $8.8 \%$ & $7.6 \%$ & $4.3 \%$ & $3.2 \%$ & $0.5 \%$ \\
\hline
\end{tabular}

Fluorescence Imaging Systems (NOVADAQ Technologies ULC, now a part of Stryker Corporation, San Jose, California). SPY improves the precise visual assessment of blood flow and tissue perfusion in extremities, peripheral vessels, and has applications in open plastic, reconstructive, cardiovascular, gastrointestinal, organ transplant surgeries and minimally invasive surgery. With over 300 peerreviewed publications, SPY has demonstrated that it can significantly reduce post-operative complications ${ }^{11-18}$.

SPY technology is available in a variety of platforms including the PINPOINT Endoscopic Fluorescence Imaging System which allows for the real-time evaluation of vascular blood supply to various anatomic structures during laparoscopic surgical procedures. OMC's adoption of PINPOINT in 2015 led to the change in surgical management of 11 patients which resulted in the avoidance of and overall reduction in anastomotic leaks ${ }^{17}$. These averted adverse events led to an average cost savings of $\$ 1,216$ per PINPOINT user per 100 cases which offset the cost of PINPOINT and its disposables after 143 cases $^{17}$. The projected cost-savings based on the clinical benefits associated with the use of PINPOINT and its anticipated adoption by all staff surgeons is expected to increase by $641 \%$ from $\$ 44,396$ in its first year of use to $\$ 329,094$ by its third year of use. The remarkably low anastomotic leak rate of the OMC study, which remain at $0.8 \%$ for patients assessed with PINPOINT, validated the results of the PILLAR II trial which demonstrated that the use of PINPOINT is safe, feasible to use with no adverse events and resulted in no anastomotic leaks in patients who had a change in surgical plan due to the intraoperative assessment of tissue perfusion provided by PINPOINT during colorectal resection $^{18}$.

\section{Summary}

In summary, healthcare providers need to embrace the growing trend towards the value-based approach and consider ways they can optimize their quality of patient care. It is inevitable that medical reimbursements will increasingly be linked to patient outcomes. Therefore, physicians and hospitals should consider investing in a quality improvement program or in new technology that will ultimately provide the best patient treatment experience and help them meet the performance metrics for which they are being penalized or rewarded.

The single institution experience at OMC has clearly shown that upfront expenditures for NSQIP can be easily justified with data-driven results if proper analysis of outcomes and institution of process changes are performed. Also, new technology that can aid in the significant reduction of complications can similarly justify its initial expense very quickly over time. While the healthcare industry continues to struggle with "cost versus quality", investing in NSQIP 
and new technology with a favorable performance profile are examples of accepting upfront expenditures with the knowledge that improvement in quality will ultimately drive down cost and result in value-based care.

\section{References}

1. Centers for Medicare \& Medicaid Services (2015) CMS Quality Measure Development Plan: Supporting the Transition to the Meritbased Incentive Payment System (MIPS) and Alternative Payment Models (APMs) (DRAFT). Baltimore, MD: Centers for Medicare \& Medicaid Services. Available from: https://www.cms.gov/ Medicare/ Quality-Initiatives-Patient-Assessment-Instruments/ Value-BasedPrograms/MACRA-MIPS-and-APMs/MACRA-MIPSand-APMs.html). Accessed on April 11, 2018.

2. Bendix J. From quantity to quality: Meeting the new demands of value-based care. Medical Economics. 2015; 92: 26-32.

3. Burwell S. Setting Value-Based Payment Goals - HHS Efforts to Improve U.S. Health Care. New England Journal of Medicine. 2015 372: 897-899.

4. U.S. Health Policy Gateway (2017). Available from: http:// ushealthpolicygateway.com/payer-trade-groups/qualitysatisfaction/ quality-improvement/general-approaches/ pay-for-performance/ pay-for-performance-in-medicare/. Accessed on April 11, 2018.

5. Centers for Medicare \& Medicaid Services (2018). Available from: https:// www.cms.gov/Medicare/Medicare-Fee-for-Service-Payment/ AcuteInpatientPPS/HAC-Reduction-Program.html. Accessed on April 11, 2018.

6. Centers for Medicare \& Medicaid Services (2018). Available from: https:// www.cms.gov/Medicare/Medicare-Fee-for-Service-Payment/ AcuteInpatientPPS/Readmissions-Reduction-Program.html. Accessed on April 11, 2018.

7. Squitieri L. Value-Based Payment Reform and the Medicare Access and CHIP Reauthorization Act (MACRA) of 2015. A Primer for Plastic Surgeons. Plast Reconstr Surg. 2017. Epub ahead of print.

8. MACRA - Frequently Asked Questions. American Society of Plastic Surgeons, 2017. Available from: https://d2wirczt3b6wjm.cloudfront. net/Health-Policy/MACRA/MACRA-FAQ.pdf. Accessed April 11, 2018.
9. The Merit-based Incentive Payment System: Quality and Cost Performance Categories. Centers for Medicare \& Medicaid Services, 2017. Available from: https://www.cms.gov/Medicare/QualityInitiatives-Patient-Assessment-Instruments/Value-Based-Programs/ MACRA-MIPS-and-APMs/QPP-MIPS-Quality-and-Cost-Slides.pdf. Accessed on April 11, 2018.

10. American College of Surgeons (2018). Available from: https:// www.facs.org/search/nsqip-participants?country=United $\% 20$ States\&page $=24$. Accessed April 11, 2018.

11. Harless CA. Tailoring through Technology: A Retrospective Review of a Single Surgeon's Experience with Implant-Based Breast Reconstruction before and after Implementation of Laser-Assisted Indocyanine Green Angiography. The Breast Journal. 2016; 22(3): 274-81.

12. Harless CA. The Clinical Efficacy and Financial Impact of Laserassisted Indocyanine Green Angiography on Implant-based Breast Reconstruction at a Large Academic Medical Center. Plastic \& Reconstructive Surgery. 2015; 135 (5S): 53.

13. Duggal CS. An Outcome Analysis of Intraoperative Angiography for Postmastectomy Breast Reconstruction. Aesthetic Surgery Journal. 2014; 34(1):61-5.

14. Sood M. Potential of the SPY intraoperative perfusion assessment system to reduce ischemic complications in immediate postmastectomy breast reconstruction. Annals of surgical intervention and research. 2013; 7(1): 1-9.

15. Chatterjee A. A Comparison of Free Autologous Breast Reconstruction with and without the Use of Laser-Assisted Indocyanine Green Angiography: A Cost-Effectiveness Analysis. Plastic and Reconstructive Surgery. 2013; 131(5): 693e-701e.

16. Komorowska-Timek E. Intraoperative Perfusion Mapping with Laser-Assisted Indocyanine Green Imaging Can Predict and Prevent Complications in Immediate Breast Reconstruction. Plastic and Reconstructive Surgery. 2010; 125(4): 1065-73.

17. Starker PM, Chinn B. Using outcomes data to justify instituting new technology: a single institution's experience. Surgical Endoscopy. 2017; 32: 1586-1592.

18. Jafari MD, Wexner SD, Martz JE, et al. Perfusion Assessment in Laparoscopic Left Sided/ Anterior Resection (PILLAR II): A MultiInstitutional Study. J Am Coll Surg. 2015; 220: 82-92. 